\title{
As dimensões da argumentação no ensino de ciências em pesquisas de 2007 a 2017: um olhar para a caracterização e para as ferramentas metodológicas para estudar esta temática
}

The dimensions of the argument in science education researches from 2007 to 2017: one to look at for the characterization and the methodological tools to study this thematic one

Agnaldo Ronie Pezarini ${ }^{1}$

Maria Delourdes Maciel ${ }^{2}$

\section{Resumo}

É de conhecimento da área acadêmica que o argumento no ensino de ciências apresenta seu viés na ação de entender e de relacionar dados e conclusões, a partir da habilidade de avaliar enunciados teóricos à luz dos dados empíricos ou procedentes de outras fontes e promover a construção da capacidade argumentativa. Neste contexto, o objetivo deste artigo é constatar no panorama e/ou cenário da pesquisa sobre Argumentação no Ensino de Ciências, quais são as ferramentas metodológicas de construção bem como as ferramentas analíticas utilizadas nas pesquisas de 2007 a 2017 e, para tanto, elaboramos um estado da arte. A metodologia empregada neste caso foi a análise de conteúdo. Os resultados apontam que o Padrão de Toulmin é a ferramenta de construção e/ou analítica mais utilizada nas pesquisas e, há outras que ora se dedicam em agregar ao Padrão de Toulmin algumas ponderações ou agem totalmente de maneira contrária a ideologia desta ferramenta tendendo muitas vezes para a argumentação focada nas premissas do discurso, de qualquer "forma" fica claro que a ferramenta contribui positivamente para a construção da argumentação.

Palavras chave: argumentação; ferramentas de construção e analítica; mapeamento.

\section{Abstract}

It is well known in the academic area that the argument in science teaching presents its bias in the action of understanding and relating data and conclusions, from the ability to evaluate theoretical statements in the light of empirical data or from other sources and to promote the construction of argumentative capacity. In this context, the objective of this article is to verify in the panorama and / or scenario of the research on Argumentation in Science Teaching, what are the methodological tools of construction as well as the analytical tools used in the researches from 2007 to 2017 and, for that, we elaborate a state of art. The methodology used in this case was content analysis. The results show that the Toulmin Standard is the most used construction and / or analytical tool in the researches, and

\footnotetext{
${ }^{1}$ Universidade Cruzeiro do Sul | rpezarini@gmail.com

${ }^{2}$ Universidade Cruzeiro do Sul | delourdes.maciel@gmail.com
} 
there are others that sometimes dedicate themselves to aggregate to the Toulmin Standard some weights or act totally contrary to the ideology of this tool tending many times for argumentation focused on the premises of discourse, from any "form" it is clear that the tool contributes positively to the construction of the argumentation.

Keywords: argumentation; construction tools and analytical; mapping.

\section{Introdução}

O Ensino de Ciências que tem sido regido nas escolas neste século está aquém da construção do letramento científico, com currículos engessados e teóricos, limitam os docentes as práticas antagônicas ao processo de construção do conhecimento científico. A afirmação que realizamos provinda da vivência no ambiente escolar está desassociada do real propósito da educação em ciências que, se deve estar pautada em ações que promovam uma construção da ciência para além das limitações das ações tradicionalistas, ou seja, deve estar pautada em um viés que preze pela construção da ciência pela argumentação. Nossa afirmação de atribuição do ensino de ciências pelas práticas argumentativas está em consonância com o pensamento de Kuhn (1993), quando disserta que:

É no argumento que nós podemos encontrar a maneira mais significativa na qual o pensamento e o raciocínio figuram na vida de pessoas comuns. Pensamento como argumento está implicado em todas as crenças que as pessoas têm, nos julgamentos que elas fazem e nas conclusões que elas tiram (KUHN, 1993, p. 322)

Argumentar é, portanto, uma ação que está para além de um simples ato classificado como simplório e banal, ele se faz essencial para o processo de formação cidadã bem como é um elemento intrínseco ao processo de construção da alfabetização científica. Corrobora com esta afirmação da supremacia e amplitude da argumentação no processo de ensino nas aulas de ciências, Motokane (2015) ao afirmar:

O desenvolvimento de habilidades argumentativas também promove a exteriorização da aprendizagem de um conteúdo ensinado quando os argumentos têm a chance de ser produzidos com base em argumentos científicos aprendidos em aula. Ao apresentarem seus argumentos, os alunos podem expressar como utilizam um determinado conceito científico para justificar uma opinião. Dessa forma, temos um indicador claro da aprendizagem do aluno. (MOTOKANE, 2015, p. 128-129)

A necessidade de se promover ações cotidianas nas aulas de ciências versadas pela argumentação garante também uma proximidade entre a vivência escolar e o contexto científico, neste caso, se faz necessário que esta aproximação ocorra, e, para além desta estreita relação constatamos que a argumentação em sala de aula garante um ensino coeso e de aplicabilidade, uma vez que os raciocínios estabelecidos pelas pessoas são em sua essência de natureza argumentativa (Kuhn 1993)

Ainda de modo a enaltecer e justificar a necessidade de que o ensino de ciências seja pautado pela argumentação, cabe salientar que promover no estudante a construção da habilidade de persuasão é de extrema importância e, esta ação está em consonância com a cultura científica, como diz Latour e Woolgar 
A capacidade de persuasão é tal que eles conseguem convencer os outros,(...) porque estão seguindo uma orientação coerente de interpretação dos dados.(...) São tão convincentes que, no contexto de seu laboratório, é possível esquecer a dimensão material do laboratório, das bancadas e a influência do passado, para consagrar-se exclusivamente aos 'fatos' postos em evidência." (Latour e Woolgar, p. 68)

Vislumbrar e concretizar nas escolas e em qualquer âmbito de ensino um ensino de ciências coeso é o que todos os docentes desta área deveriam almejar e planejar, pois assim como nos alerta Lemke (1997):

ao ensinar ciência, ou qualquer matéria, não queremos que os alunos simplesmente repitam as palavras como papagaios. Queremos que sejam capazes de construir significados essenciais com suas próprias palavras [...] mas estas devem expressar os mesmos significados essenciais se hão de ser cientificamente aceitáveis. (LEMKE, 1997, p. 105)

Contudo a argumentação é uma das ferramentas que possibilitam um ensino de ciências em consonância com as práticas científicas e, identificar no âmbito da pesquisa quais são as ferramentas de construção, bem como as ferramentas analíticas que embasam este processo do letramento científico com ênfase nos processos argumentativos se faz necessários tanto para o cenário da pesquisa acadêmica, quanto para o cenário escolar, onde as pesquisas devem de fato atuar e promover ressignificações.

\section{Metodologia}

O objetivo deste artigo é constatar no panorama e/ou cenário da pesquisa sobre Argumentação no Ensino de Ciências, quais são as ferramentas metodológicas de construção bem como as ferramentas analíticas utilizadas nas pesquisas de 2007 a 2017. Para tanto, têm como base ações metodológicas do levantamento bibliográfico e, em linhas gerais se classifica como um estado da arte.

É preciso justificarmos que, a construção deste artigo está pautada nas premissas do estado da arte e, está em consonância com o pensar de Fiorentini (1993), que nos alerta sobre a importância de se realizar uma pesquisa identificar aquilo que já está sendo ou foi estudado no cenário acadêmico. Contudo, à luz de Fiorentini (1993) justificamos a nossa opção pelo estado da arte, pela descrição do referido autor:

Apenas uma pequena parcela (de educadores e pesquisadores) tem procurado verificar o que os colegas já investigaram a respeito de seu tema ou problema de pesquisa. Alguns justificam sua prática dizendo que os outros trabalhos não possuem o mesmo referencial teórico ou que não se inserem na mesma linha de pesquisa. Ora, não consultamos e citamos outros trabalhos apenas para lhes dar continuidade ou para buscar apoio às nossas ideias. Fazemos isso também para questionar ou até refutar seus pressupostos ou suas conclusões e encaminhamentos. (FIORENTINI, 1993, p. 56)

É em Ferreira (2002) que enaltecemos as ações constituintes de um estado da arte ou estado do conhecimento que se caracterizam como um levantamento bibliográfico. 
Definidas como de caráter bibliográfico, elas parecem trazer em comum o desafio de mapear e de discutir uma certa produção acadêmica em diferentes campos do conhecimento, tentando responder que aspectos e dimensões vêm sendo destacados e privilegiados em diferentes épocas e lugares, de que formas e em que condições têm sido produzidas certas dissertações de mestrado, teses de doutorado, publicações em periódicos e comunicações em anais de congressos e de seminários. Também são reconhecidas por realizarem uma metodologia de caráter inventariante e descritivo da produção acadêmica e científica sobre o tema que busca investigar, à luz de categorias e facetas que se caracterizam enquanto tais em cada trabalho e no conjunto deles, sob os quais o fenômeno passa a ser analisado. (FERREIRA, 2002, p. 258)

A partir do objetivo de constatar quais são as ferramentas de construção e de análise que regem as pesquisas sobre Argumentação no Ensino de Ciências, a partir de um levantamento bibliográfico nos meios de produção e divulgação científica que constam na tabela 1, construímos o estado da arte. A busca nos meios de divulgação e ou produção acadêmica se fez pelo descritor argumentação e, na continuidade realizamos os procedimentos que constam na análise de Bardin (2006).

Quando se tem como propósito realizar uma análise de conteúdo em busca de questões específicas que expressem explicitação, sistematização e expressão do conteúdo de mensagens, Bardin (2006) aponta que esta ação é possível promover a análise de conteúdo pautada nas premissas citadas em sua obra, isso é possível a partir de ações compostas em três fases, sendo elas: a) pré-análise; b) exploração do material e c) tratamento dos resultados, inferência e interpretação.

Especificamente as fases apresentam peculiaridades e obrigatoriedades a serem rigorosamente seguidas. No que se refere à fase de pré-análise primordialmente se tem vistas a organização do material de forma a organizar as ideais iniciais. Segundo Silva et al (2017) à luz de Bardin (2006) a fase de pré-análise apresenta as peculiaridades conforme descrito pelos autores citados:

Compreende a realização de quatro processos: (i) a leitura flutuante (estabelecer os documentos de coleta de dados, o pesquisador toma conhecimento do texto, transcreve entrevistas); (ii) escolha dos documentos (seleção do que será analisado); (iii) formulação de hipóteses e objetivos (afirmações provisórias, que o pesquisador se propõe a verificar); (iv) elaboração de indicadores, através de recortes de textos nos documentos analisados, os temas que mais se repetem podem constituir os índices. (SILVA et al, 2017, p. 171)

A partir da realização da leitura flutuante em busca de dados específicos, identificamos e elencamos as categorias foco, que consideramos pertinentes à temática e, de posse desta seleção. Vale ressaltar o quão é de suma importância se ater e dedicar frente a esta fase do processo, como salienta Bardin (2006):

Nesta fase, é importante que se atente aos seguintes critérios na seleção dos documentos (BARDIN, 2006): - Exaustividade: atentar para esgotar a totalidade da comunicação; • Representatividade: os documentos selecionados devem conter informações que representem o universo a ser pesquisado; - Homogeneidade: os dados devem referir-se ao mesmo 
tema; - Pertinência: os documentos precisam ser condizentes aos objetivos da pesquisa. (SILVA et al, 2017, p. 171)

Vislumbramos na primeira fase a expressividade de uma análise textual com embasamento teórico à luz de Bardin (2006), onde se identifica as etapas de constituição de uma análise em busca de um viés com coerência e coesão. O processo de construção desta análise na perspectiva da autora em foco, tem sua continuidade nas ações de exploração do material e tratamento dos resultados, inferência e interpretação.

Em linhas gerais a segunda fase, que se refere à exploração do material, esta tem vistas ao processo de exploração para identificação e construção das categorias de análise, ou seja, a a partir da análise do material coletado, se deve buscar por elementos de análise que expressem a caracterização do estudo para com a argumentação. Nesta etapa é preciso atenção para que essas categorias sejam construídas a partir de um critério de exclusividade, ou seja, uma informação deve pertencer a apenas uma categoria mesmo que esta tenha relação com outra e, com isso promover a categorização dos elementos constituintes em um só parâmetro. (BARDIN, 2006)

Para finalizar o processo de análise na perspectiva de Bardin (2006), é preciso se ater as prerrogativas de como agir e atuar frente às categorizações realizadas na segunda fase, ou seja, qual é o olhar de análise e foco do estudo. À luz de Bardin (2006), Silva et al (2017), nos diz que esse processo apresenta as seguintes peculiaridades:

A terceira e última etapa consiste no tratamento dos resultados, inferência e interpretação. Nesta etapa ocorre a condensação e o destaque das informações para análise, culminando nas interpretações inferenciais; é o momento da intuição, da análise reflexiva e crítica. (SILVA et al, 2017, p. 172).

Tabela I - Lócus de Pesquisa para identificação da Pesquisas/Trabalhos.

\begin{tabular}{|c|c|}
\hline \multicolumn{2}{|l|}{ Lócus de Pesquisa } \\
\hline Descrição do Lócus de Pesquisa & Quantidade \\
\hline Banco Digital de Teses e Dissertações & 31 \\
\hline Encontro Nacional de Pesquisa em Educação em Ciências - 2007 & 06 \\
\hline Encontro Nacional de Pesquisa em Educação em Ciências - 2009 & 07 \\
\hline Encontro Nacional de Pesquisa em Educação em Ciências - 2011 & 24 \\
\hline Encontro Nacional de Pesquisa em Educação em Ciências - 2013 & 19 \\
\hline Encontro Nacional de Pesquisa em Educação em Ciências - 2015 & 17 \\
\hline Encontro Nacional de Pesquisa em Educação em Ciências - 2017 & 17 \\
\hline Revista Electrónica de Enseñanza de las Ciencias & 03 \\
\hline Periódico Scielo & 06 \\
\hline Amazônia: Revista de Educação em Ciências e Matemática & 02 \\
\hline Caderno Brasileiro de Ensino de Física & 05 \\
\hline Revista Ciência \& Educação - Bauru - UNESP & 09 \\
\hline Revista Ensaio - Pesquisa em Educação em Ciências - UFMG & 19 \\
\hline Revista Investigações em Ensino de Ciências - IENCI - UFRGS & 14 \\
\hline Revista Brasileira de Pesquisa em Educação em Ciências & 04 \\
\hline Total de pesquisas/trabalhos & 183 \\
\hline
\end{tabular}

Pautando portanto na perspectiva de Bardin (2006), sequencialmente nos dedicamos a segunda fase do processo de análise e, estabelecemos como categorias de análise as que seguem: ano de realização/publicação; Instituição de Ensino Superior de origem; disciplina 
da área da Ciência da Natureza; tipo/Viés de Estudo (Bibliográfico ou Empírico); ferramenta de Construção e Ferramenta Analítica. Para contemplar as três fases do processo, demos continuidade realizando a análise e interpretação dos resultados a partir do descritor, argumentação, nas bases de dados e/ou lócus de pesquisa listadas na tabela 1 e, na sequência, a partir dos dados obtidos para as categorias elencadas construímos gráficos que expressam as informações obtidas para análise e discussões.

Tendo descrito os parâmetros de construção deste artigo, cabe salientar a importância do processo de argumentação no ensino de ciências quando se tem como propósito um ensino de qualidade. Logo, devemos salientar o quanto existe de especificidades nas práticas voltadas a esta temática e, à luz de Jiménez-Aleixandre e Diaz Bustamante, 2003, p. 360, ratificamos a grandiosidade e a peculiaridade do processo, quando os autores citam "Por argumento entende-se a capacidade de relacionar dados e conclusões, de analisar enunciados teóricos à luz dos dados empíricos ou procedentes de outras fontes".

\section{Resultados e discussões}

A análise dos 183 documentos, que se referem a artigos, trabalhos publicados em eventos bem como teses e dissertações defendidas, relevam dados significativos frente ao panorama da pesquisa em argumentação. Os dados desta análise serão revelados na sequência, mas de antemão salientamos a expressividade das pesquisas.

\section{Ano de publicação}

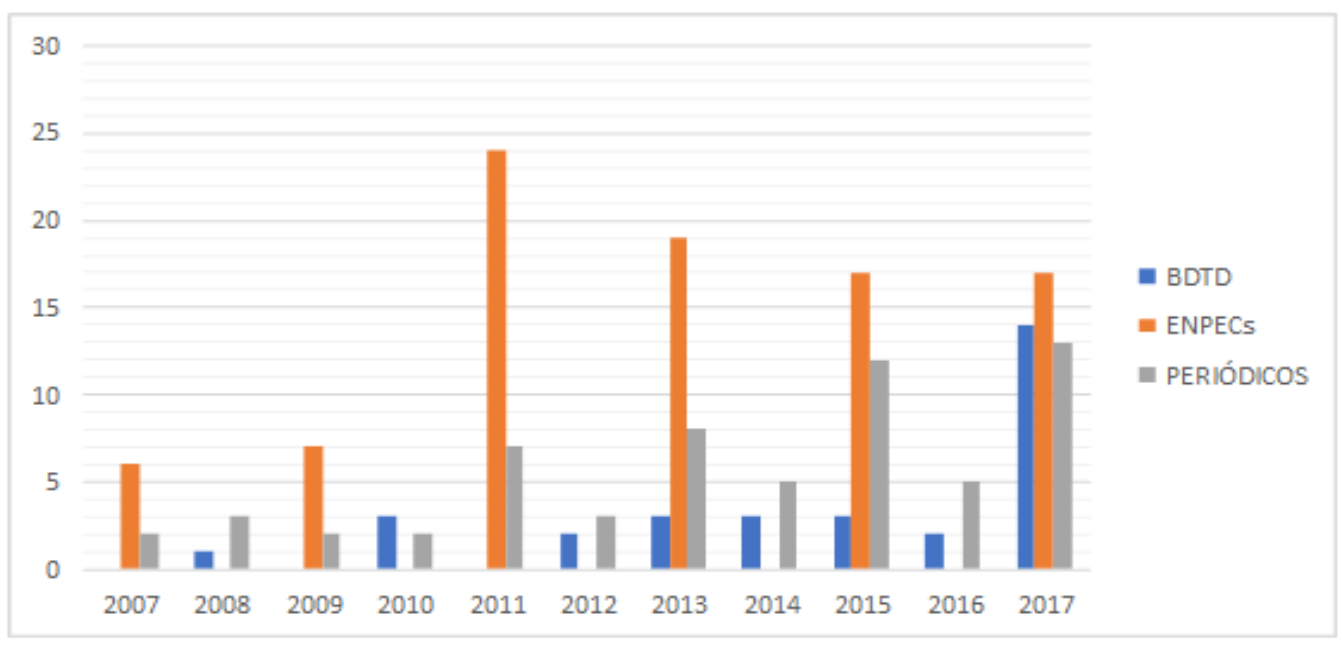

Figura I: Produtividade anual de 2007-2017 - Lócus: BDTD - ENPEC - PERIÓDICOS

De modo pontual e específico se pode verificar uma maior produção em termos quantitativos para os anos de 2015 e 2017 para as publicações em revistas cientificas da área. Um outro aspecto importante que se pode verificar com a análise da figura 1 é poucos trabalhos foram encontrados nãos periódicos explorados e, um número expressivo no ENPECs, já a produção acadêmica nos cursos de pós-graduação se mostra significativa. Vale apontar que os trabalhos que se encontram no ENPEC se tratam de pesquisas acadêmicas que dialogam tanto na vertente teórica quanto empírica, de modo que, o rol dos trabalhos garantem uma fonte de dados privilegiada frente a produção com o viés do Ensino de Ciências e suas vertentes de práticas de ensino, metodologias de ensino que se fazem 
presentes nas prática dos docentes e pesquisadores do nosso país e, dentro deste contexto pode-se concluir que o interesse pela temática argumentação tem crescido nos últimos anos e, as produções são visíveis neste encontro que se trata de um evento de expressão para a área do Ensino de Ciências.

\section{Instituiç̧ão de ensino superior de origem}

As pesquisas sobre a argumentação têm sido realizadas em diversas Instituições de Ensino no Brasil, existindo maior incidência de produção em Instituições de Ensino Superior específicas, como mostra a figura II. Para este item de especificidade de busca por pesquisas sobre argumentação, vale salientar que, a busca se deu por meio se ateve a uma leitura flutuante no Google acadêmico para identificar as IES com produtividade acadêmica na temática. Salientamos a expressiva produtividade nas instituições: Universidade de São Paulo (USP); na Universidade Federal de Minas Gerais (UFMG); na Universidade Federal do Pernambuco; na Universidade Federal do Rio de Janeiro e produtividade relativa em outras instituições.

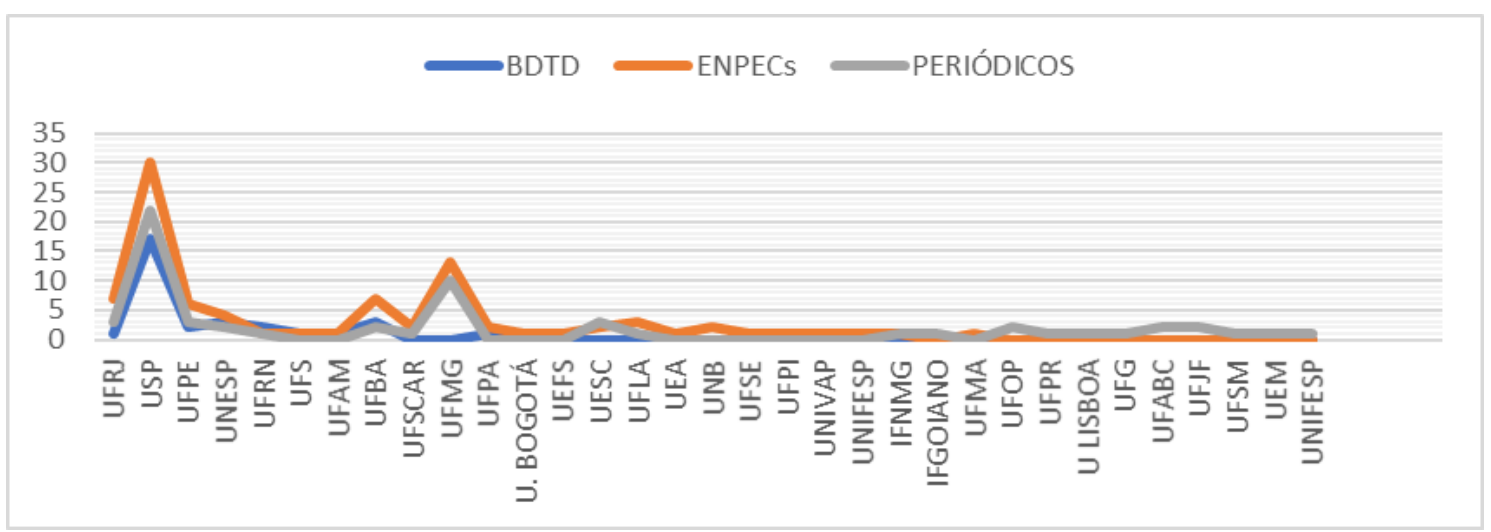

Figura II - Instituições de Ensino Superior de Origem das Pesquisas/Trabalhos.

\section{Disciplina da área da ciência da natureza}

O levantamento a partir do descritor argumentação nos periódicos foco deste mapeamento bem como os trabalhos apresentados nos ENPECs e os que constam no BDTD para o período estipulado revelam que a argumentação no ensino de ciências está presente em todas subáreas (Biologia, Ciências, Química e Física) da Ciência da Natureza

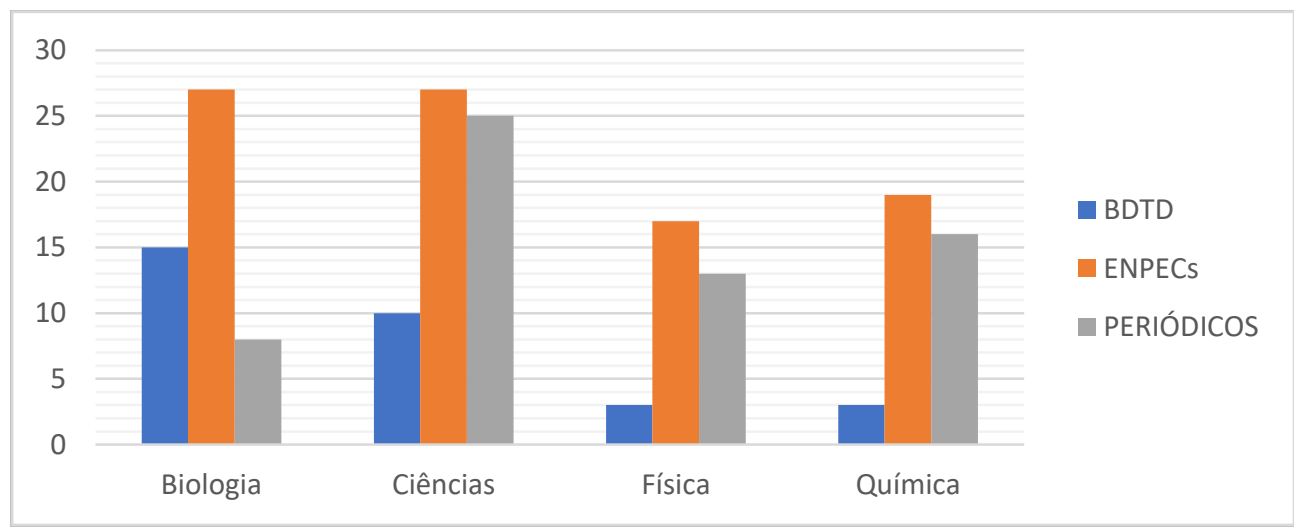

Figura III - Disciplina da Ciência da Natureza em foco na Pesquisa/Trabalho. 


\section{Tipo de estudo (bibliográfico e/ou empírico)}

Fica constatado que quando as pesquisas se referem à temática argumentação no Ensino de Ciências, a pesquisa do tipo empírica é a de maior frequência. Este dado está em consonância com os objetivos das pesquisas desta natureza, uma vez que, as pesquisas que encontramos dialogam em sua grande maioria de processos de construção da argumentação e da qualidade das argumentações produzidas nestes processos.

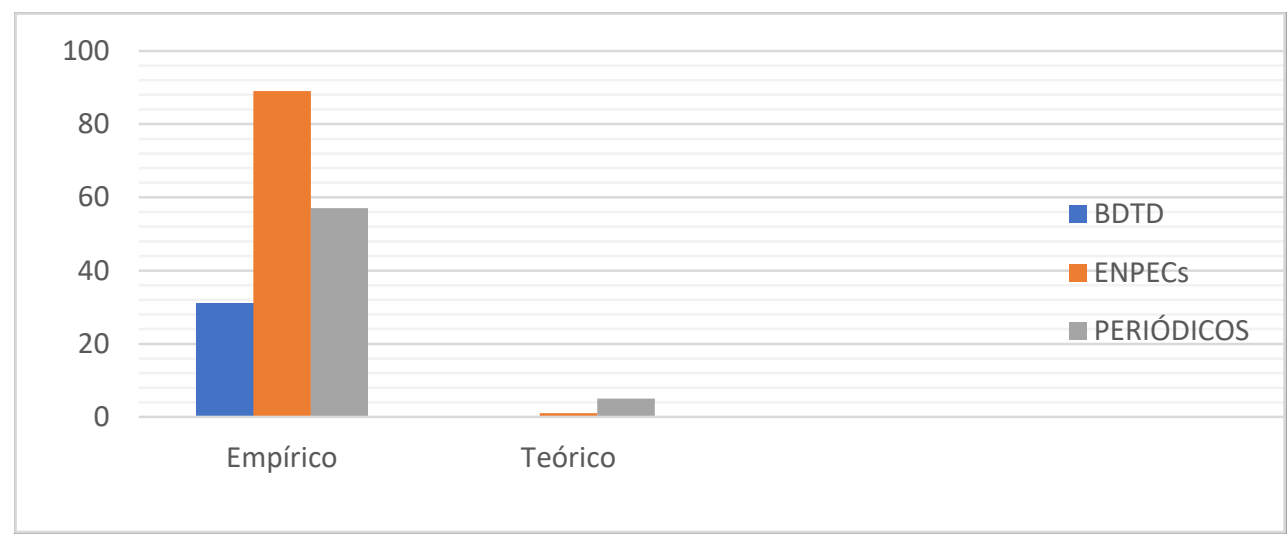

Figura IV - Tipo de Estudo (Empírico ou Teórico).

\section{Ferramenta de construção e analíticas da argumentação no ensino de ciências}

As pesquisas sobre argumentação no Ensino de Ciências recorrem à referenciais teóricos que discutem e abordam esta temática com base em padrões, que visam os meios para se promover, analisar, constatar, construir e identificar a qualidade da argumentação. Como resultado da análise das produções analisadas verificamos que existe um Padrão, neste caso o TAP (Toulmin's Argument Pattern), de maior ênfase nos trabalhos, no entanto, para além deste, encontramos outros que regem os trabalhos singularmente ou em conjunto com este de maior ênfase. O Padrão de maior ênfase para as pesquisas em Argumentação no Ensino de Ciências é o TAP, Padrão de Toulmin, neste caso, Stephen Toulmin (1958) propõe uma abordagem estrutural dos elementos constitutivos do raciocínio argumentativo. Distingue entre os elementos invariáveis, que dizem respeito à forma, e nesse sentido, são independentes do assunto de que se trate) e os elementos variáveis, isto é, que dependem do tipo de assunto em questão, no entanto ele não é a única ferramenta metodológica, como mostra a tabela II.

Diante da constatação de que há inúmeras ferramentas de construção, bem como, analíticas da argumentação no Ensino de Ciências, salientamos que o Padrão de Toulmin é a ferramenta de construção e também a ferramenta analítica de maior evidência nas pesquisas e, de modo a dialogar sobre as especificidades destas ferramentas faremos uma breve discussão do Padrão de Toulmin e daquelas que estiveram presentes como construtoras dos processos de argumentação em seis ou mais pesquisas e, são elas: Pragma Dialética; Pereleman e Olbrechts-Tyteca; Júri Simulado; Lawson; Quadro Analítico de Rainbow; Platin; Driver, Newton e Osborne; Jimenez et al; Simon Erduran e Osborne. 
Tabela II: Ferramentas de Construção e Analítica da Argumentação em Pesquisas de 2007 a 2017. Ferramentas de Construção da Argumentação segundo Pesquisas de 2007 a 2017

\begin{tabular}{l|c|c|c|c|c|c}
\hline Ferramenta de construção e/ou analítica & \multicolumn{2}{|c|}{ BDTD } & \multicolumn{2}{c|}{ ENPECS } & \multicolumn{2}{c}{ PERIÓDICOS } \\
\hline Toulmim & 20 & 18 & 59 & 46 & 32 & 32 \\
\hline Etnografia interacional & 00 & 00 & 03 & 00 & 01 & 01 \\
\hline Simon, Erduran e Osborne & 02 & 03 & 03 & 04 & 02 & 02 \\
\hline Ducrot & 00 & 00 & 01 & 01 & 00 & 00 \\
\hline Kock & 01 & 01 & 01 & 02 & 00 & 00 \\
\hline Jiménez et al & 01 & 01 & 02 & 05 & 02 & 02 \\
\hline Maloney y Simon & 00 & 00 & 00 & 01 & 00 & 00 \\
\hline Driver, Newton e Osborne & 01 & 01 & 03 & 03 & 03 & 03 \\
\hline Mcneill e Krajcik & 00 & 01 & 00 & 01 & 00 & 00 \\
\hline Suart; Marcondes 2009 & 01 & 01 & 00 & 01 & 00 & 00 \\
\hline Plantin & 00 & 00 & 01 & 01 & 02 & 02 \\
\hline Quadro Analítico de Rainbow & 01 & 01 & 03 & 03 & 00 & 00 \\
\hline Lawson & 00 & 00 & 03 & 03 & 00 & 00 \\
\hline Raciocínio Informal (RI). & 00 & 00 & 00 & 01 & 00 & 00 \\
\hline Juri Simulado & 00 & 00 & 02 & 02 & 01 & 01 \\
\hline Lógica Filosófica & 00 & 00 & 01 & 01 & 01 & 01 \\
\hline Wenzel & 00 & 00 & 01 & 00 & 00 & 00 \\
\hline SEBBI & 01 & 01 & 01 & 01 & 00 & 00 \\
\hline Práticas e Movimentos Epistêmicos & 00 & 00 & 00 & 01 & 02 & 02 \\
\hline Penha \& Carvalho & 00 & 00 & 00 & 02 & 01 & 01 \\
\hline Discurso do Sujeito Coletivo & 00 & 00 & 01 & 01 & 00 & 00 \\
\hline Análise Textual Discursiva & 00 & 00 & 01 & 01 & 00 & 00 \\
\hline Freire & 00 & 00 & 01 & 01 & 00 & 00 \\
\hline Perelman e Olbrechts-Tyteca & 02 & 02 & 01 & 01 & 00 & 00 \\
\hline Argument Driven Inquiry & 00 & 00 & 01 & 01 & 00 & 00 \\
\hline POA & 00 & 00 & 00 & 00 & 01 & 01 \\
\hline Berland \& McNeil & 00 & 00 & 00 & 02 & 00 & 00 \\
\hline Procedimentos Discursivos Didáticos & 00 & 00 & 00 & 00 & 02 & 02 \\
\hline Filosofia Lakatosiana & 00 & 00 & 00 & 00 & 01 & 01 \\
\hline Billig & 00 & 00 & 00 & 00 & 02 & 02 \\
\hline TDC - Textos de Divulgação Científica & 00 & 00 & 01 & 01 & 00 & 00 \\
\hline Lógica Informal & 00 & 00 & 00 & 00 & 01 & 01 \\
\hline Assis & 00 & 00 & 00 & 00 & 01 & 01 \\
\hline Propósitos Epistêmicos & 00 & 00 & 00 & 00 & 01 & 01 \\
\hline Ferramenta do Argumento Central - CAF & 01 & 01 & 00 & 00 & 00 & 00 \\
\hline Pragma dialética - Van Eemeren et al & 00 & 00 & 00 & 01 & 04 & 04 \\
\hline Teoria da Ação Mediada & 00 & 00 & 00 & 01 & 00 & 00 \\
\hline Kelly e Takao & & 00 & 00 & 00 & 02 & 02 \\
\hline
\end{tabular}

Sendo o Padrão de Toulmin o de maior evidência e aplicabilidade nas pesquisas, cabe elucidar e caracterizar esta ferramenta. O referido padrão apresenta, no que se refere à sua identidade e elementos constituintes, algumas especificidades conforme nos apontadas Scarpa e Trivelato:

O objetivo da investigação de Toulmin é caracterizar o processo racional da produção de argumentos produzidos em diversas esferas da sociedade, "(...)os procedimentos e as categorias mediante os quais se podem discutir e decidir todas as "causas"." (TOULMIN, 1958/2006, p.10). 
Entendendo o artigo científico como um texto predominantemente argumentativo e buscando investigar justamente as características dessa estrutura argumentativa, os dois motivos apresentados anteriormente justificam a escolha desse referencial para realizarmos a análise dos artigos científicos. Para haver um argumento, "é preciso apresentar dados de algum tipo; uma conclusão pura, sem quaisquer dados apresentados em seu apoio, não é um argumento" (TOULMIN, 1958/2006, p. 152). O passo que autoriza o estabelecimento de uma afirmação $C$ a partir dos dados $D$ é chamado de garantia (W). A garantia é a informação a partir da qual argumentamos. No entanto, a garantia somente será válida em virtude de certos fatos, observações, experimentos, leis e conhecimentos mediante os quais foram estabelecidas. As garantias têm avais que permitem sua formulação, apoios (B) que a tornam aceitáveis. As garantias possuem qualificadores modais $(\mathrm{Q})$ que emprestam força às conclusões - termos como certamente, presumivelmente, provavelmente, necessariamente, quase nunca -, além de circunstâncias excepcionais que, em casos específicos, podem ser refutadas (R). Quando a conclusão não apresenta ganho significativo de informação com relação à garantia, o argumento é considerado analítico. Neles, a conclusão é resultado óbvio dos dados e da garantia, como se apenas o embaralhamento das premissas fosse suficiente para se chegar à conclusão. Toulmin afirma que esse tipo de argumento é raro na prática cotidiana e os distingue de argumentos substanciais. Nestes, o argumento nunca é tautológico e as informações que permitem passar dos dados à conclusão são relevantes e substanciais. (SCARPA \& TRIVELATO, 2011, p. 4)

Alguns pesquisadores de renome promoveram ao longo da aplicabilidade do Padrão de Toulmin algumas retificações no sentido de promover acréscimos ao padrão base, como por exemplo, a pesquisa Jiménez-Aleixandre, como aponta Moreira et al (2011)

Jiménez Aleixandre (1998) propôs um complemento ao modelo de Toulmin, classificando os dados (D) como sendo dado fornecido (DF), dado obtido (DO), dado empírico (DE) ou dado hipotético (DH). Dessa maneira, a análise das transcrições do presente trabalho também contou com o auxílio desse método de avaliação. (MOREIRA et al, 2011, p. 7).

Para além de promover acréscimos e ponderar acerca do Padrão de Toulmin, JiménezAleixandre realiza também a análise dos argumentos de forma específica, sendo que suas ações são caracterizadas como uma ferramenta analítica específica, sendo que esta considera segundo Pereira \& Trivelato (2011) que:

O presente estudo utiliza categorias inspiradas naquelas elaboradas por Jiménez et al (1998), que são aquelas associadas com o trabalho de explicação e justificação dos cientistas. Nossas categorias de análise relacionadas as operações epistêmicas estão descritas a seguir. Definição, Explicações, Coerência e Plausibilidade: Os autores descrevem que a plausibilidade está associada ao tipo de explicação enunciada em um determinado campo. A plausibilidade está associada a avaliação e aplicação de conhecimentos do campo em questão. Tem a ver com o que Toulmin (2006) associa com campo-dependência. Uma explicação é plausível em ciência, quando carrega explicações e conceitos razoáveis e aceitos pela comunidade científica. (PEREIRA \& TRIVELATO, 2011, p. 5) 
Jiménez-Aleixandre analisa e age para com as questões da argumentação de forma específica quanto as especificidades de temáticas Sociocientíficas, a pesquisadora, segundo De Souza e Gehlen (2015), afirma que a argumentação neste caso quando centrada nestas questões deve:

Entre as propostas preocupadas com a abordagem de questões sociocientíficas em sala de aula encontra-se a Argumentação centrada em questões sociocientíficas, discutida por Jiménez-Aleixandre (2010), a qual preocupa-se, dentre outros aspectos, com o desenvolvimento do pensamento crítico dos educandos, compreendido como a "capacidade de desenvolver uma opinião independente, adquirindo a faculdade de refletir e atuar sobre a realidade" (p. 40, tradução nossa). Para a autora, o pensamento crítico apresenta duas dimensões: uma relacionada com a argumentação, ao uso e a busca de provas, e outra relacionada com a emancipação social, isto é, ao desenvolvimento da opinião independente e análise crítica dos discursos que justificam as desigualdades. (DE SOUZA \& GEHLEN, 2015, p. 2)

A argumentação no Ensino de Ciências está em muitas pesquisas pautada no viés de outro estudioso, no caso Lawson, que parte de questões de raciocínio hipotético para a busca da construção da argumentação.

Lawson (2004) propõe o raciocínio hipotético-dedutivo como uma das principais formas de inferir dos cientistas e de produzir conhecimento. A estrutura tem seu início com o termo "Se...", diretamente ligado às hipóteses (uma proposição); o termo "E..." diz respeito ao acréscimo de condições de base (um teste); o termo "Então..." é relativo aos resultados esperados (às consequências esperadas); o termo "E..." ou "Mas..." aos resultados e consequências reais e verdadeiras. O termo "E..." deve ser utilizado caso os resultados obtidos combinem com os esperados e o termo "Mas...", caso haja um desequilíbrio nos resultados; desta forma, o ciclo reinicia-se com outras hipóteses e, finalmente, o termo "Portanto..." introduz a conclusão a que se chega (LOCATELLI, 2006, p. 27).

Uma especificidade da teoria de Lawson é promover no ambiente escolar o pensar para o ensino de ciências de fato condizente as premissas do pensar cientificamente, dando ênfase a ações de apontamento de hipótese e de busca explicações para esta hipótese. As especificidades destas ações podem ser identificadas à luz de Freire \& Motokane (2013), quando afirmam:

Segundo Lawson, etapas recorrentes no pensar cientificamente envolvem: 1) observação de um fenômeno que gere interesse pela 2) proposição de um mecanismo causal capaz de explicá-lo (formulação de uma hipótese ou explicação); 3) previsão sobre o comportamento do fenômeno mediante a causa hipotetizada usando o conhecimento prévio como garantia (condições de base) para os resultados esperados; 4) teste da hipótese observando os efeitos reais decorrentes da causa proposta e comparando-os com os efeitos esperados; e 5) conclusão sobre a validade da hipótese formulada. Ao estabelecer etapas claras que orientam o desenvolvimento de asserções de conhecimento, o raciocínio hipotético dedutivo segundo o padrão de Lawson (2004) tem sido usado para investigar o processo argumentativo. (FREIRE \& MOTOKAME, 2013, p. 2) 
Dialogar sobre a argumentação no Ensino de Ciências requer que nos pautemos no real conceito da ação, já que a mesma difere daquela existente na argumentação presente na língua materna. Outros pesquisadores a fazem de modo específico e, de acordo com seus vieses, tal como o faz Eemeren, Grootendorst e Kruiger bem como Leitão e Almeida, quando discutem esta concepção da seguinte forma:

Com relação à argumentação, Eemeren, Grootendorst e Kruiger (1987) apontam que ela é uma atividade social de natureza discursiva, na qual indivíduos expressam pontos de vista diferentes sobre um tema defendendo seus posicionamentos com vista a convencer seus interlocutores. Já para Leitão e Almeida (2000), a argumentação é uma atividade que envolve uma multiplicidade de perspectivas e pressupõe oposição entre as opiniões dos envolvidos. Assim, entende-se que, no contexto da sala de aula, a argumentação é uma forma de interação comunicativa em que docentes e alunos confrontam seus saberes e opiniões sobre um tema com o propósito de convencer um ao outro, a partir de critérios científicos. (SILVA et al, 2011, p.3)

Outras ferramentas de construção e de análise da argumentação se pautam nas premissas das questões e dos vieses do discurso como é o caso da Etnografia Interacional, dos Procedimentos Discursivos Didáticos (PDD) bem como o posicionamento de Platin (2008).

Evidenciamos que o discurso se caracteriza como uma prática e/ou ação intrínseca ao processo ou aos procedimentos da argumentação. Para além do que já fora apresentado e discutido, é preciso salientar a importância de Plantin (2008) que versa sua teoria também acerca das questões do discurso, conforme nos diz à luz deste pensador.

O modelo dialogal (PLANTIN, 2008) fundamenta-se na noção de contradição ativa dos discursos em torno de uma questão. Assim, a atividade argumentativa se inicia quando se coloca em dúvida um ponto de vista, sendo definida pelo desenvolvimento e pelo confronto de pontos de vista em contradição, em resposta a uma mesma pergunta. Uma noção importante, na abordagem argumentativa dialogal, é a de pergunta argumentativa. Para esclarecê-la, Plantin (2008) discorre sobre os papéis argumentativos em função dos atos de propor, opor-se e duvidar. Assim, aqueles que manifestam uma proposição contrária a um enunciado que manifesta uma opinião dominante, são denominados proponentes. Os locutores que se opõem ao(s) proponente(s) são os oponentes. Aqueles que não se identificam com nenhum dos dois discursos - do proponente e do oponente - estão na posição de terceiros e transformam a oposição em pergunta. Em outras palavras, a pergunta argumentativa origina-se da contradição entre discurso e contra discurso. (MENDES \& SANTOS, 2013, p.2)

Outro autor que enfatiza suas ações e seus ideais frente ao discurso é Van EEMEREN, no entanto, este autor se preocupa com maior ênfase na análise textual produto de um contexto verbal de interação em uma atividade social ou em que se possa estar inserido, Cirino \& Souza (2008) apontam as especificidades da ideologia de Van Eemeren ao dialogarem:

Fazer uma análise textual implica definir e identificar unidades de análise, que são os elementos de base a serem categorizados na sequência do 
trabalho. A partir das transcrições das falas dos estudantes considera-se como unidade básica de análise um "enunciado". Ela é constituída de um conjunto de um ou mais posicionamentos com objetivo de obter aprovação de determinado ponto de vista. Estes posicionamentos podem ser expressos em um ou mais "enunciados". (CIRINO \& SOUZA, 2008, p. 123)

Levando em consideração e, se pautando nas questões que nos revelam Plantin (2008), outra estratégia que se caracteriza como ferramenta de construção e de análise da argumentação é o Júri simulado. Esta ferramenta nos aponta algumas características específicas, sendo elas segundo De Melo et al 2015:

Em situações de júri simulado, são possíveis três papéis argumentativos distintos (Plantin, 2008): o proponente, o oponente e o terceiro. 0 proponente defende uma opinião, o oponente defende outra opinião, geralmente contrária à primeira, e o terceiro assume a posição de juiz, que deve ponderar sobre o mérito das bases racionais dos argumentos a favor e contra a opinião em jogo. Os júris simulados e a alternância de papéis argumentativos nessas atividades podem contribuir para viabilizar argumentações de qualidade. (ZEIDLER et. al, 2005). (DE MELO et al, 2015. p.3)

Vislumbramos nesta ferramenta para as ações relacionadas a argumentação no Ensino de Ciências que o discurso deve ser uma ação fortemente encorajada e presente no âmbito escolar, em especial para com as disciplinas da Ciência da Natureza, uma vez que, é preciso que o discente em formação seja conduzido a construção da habilidade argumentativa.

A estratégia identificada como Pragma Dialética é outra ferramenta utilizada para a argumentação que tem o propósito de ação para melhor compreender o processo de argumentação nas práticas educativas, conforme o diálogo de SOUTO et al (2011)

Para os autores da teoria Pragma-dialética, a "Estrutura da Argumentação" refere-se à relação entre um ponto de vista e seus argumentos. Esses são elementos utilizados para apoiar ou refutar um ponto de vista. No presente estudo, utilizamos a expressão "Situação argumentativa" para indicar o conjunto de pontos de vista e seus argumentos envolvidos no processo de resolver diferenças de opinião subordinadas e principal relacionadas a um mesmo tema. Além disso, quando utilizamos a expressão "processo da argumentação" estamos nos referindo às interações entre os participantes e às formas como o professor usa a linguagem durante as situações. (SOUTO et al, 2011, p. 4)

Outras estratégias e/ou ferramenta identificada em nosso estudo pertence aos pesquisadores Driver, Newton e Osborne 2000. Segundo BIASOTO \& CARVALHO, 2007, p. 3, à luz dos autores, "a argumentação pode ser considerada como uma atividade individual, através do pensamento e escrita ou, socialmente feito em grupo e pode ser entendida como promover um raciocínio para ou contra uma proposição ou conduta".

As ações segundo os autores Driver, Newton e Osborne devem prover que o estudante desenvolva o seu próprio raciocínio, bem como distingue a argumentação em dois tipos, a retórica e a dialética.

As ações voltadas para a Argumentação nas aulas de Ciências devem ser analisadas de modo a identificar as articulações e as ponderações específicas em textos elaborados pelos alunos, neste caso, Perelman e Olbrechts-Tyteca, presente também em pesquisas/trabalhos 
de nosso mapeamento, utiliza-se de ideias e vieses específicos e salientam que segundo SOUSA (2017) que

Perelman e Olbrechts-Tyteca (1996) desenvolvem ideias de argumentação com o objetivo de mostrar "que as mesmas técnicas de argumentação se encontram em todos os níveis, tanto na discussão ao redor da mesa familiar como no do debate num meio muito especializado. No entanto, Perelman e Olbrechts-Tyteca (1996) destacam que nesse processo podemos estar sujeitos a interpretar de forma errônea o sentido real que o orador queira mencionar. (SOUSA, 2017, p. 2)

Osborne et al apresenta um referencial de qualidade que está versado sobre níveis como nos descreve Da Silva \& Da Silva (2011)

Quanto à qualidade do argumento Osborne et al. (2004a), estruturaramna conforme a presença ou ausência de refutações a partir de argumentos individuais e coletivos. Definiram, dessa forma, cinco (5) níveis de uso de refutações como indicadores da qualidade da argumentação, conforme quadro de Níveis de qualidade da argumentação que descreve: Nível 1 A argumentação consiste de argumentos que são uma afirmação simples versus uma contra-afirmação ou uma afirmação versus uma afirmação; Nível 2 A argumentação tem argumentos consistindo de uma afirmação bem como dados, garantias ou apoio, mas não contém qualquer refutação; Nível 3 A argumentação tem argumentos com uma série de afirmações ou contra- afirmações com um dado, garantias ou apoio com uma refutação fraca ocasional; Nível 4 A argumentação mostra argumentos com uma formação com uma refutação identificável e clara. Cada argumento pode conter várias afirmações ou contra-afirmações; Nível 5 A argumentação apresenta um argumento mais amplo com mais de uma refutação. (Da Silva \& Da Silva, 2011, p. 6)

Contudo, evidenciamos com este mapeamento que a temática argumentação no Ensino de Ciências é presente nas pesquisas sobre o Ensino de Ciências, as mesmas versam e dialogam em sua grande maioria das ferramentas de construção uma vez que as pesquisas se voltam para o desenvolvimento da argumentação nos alunos e/ou nos docentes em formação e, para além desta ação de construção, fica evidente que, para as pesquisas, não basta apenas ter a competência e a habilidade para com a construção da argumentação no ensino de ciências, uma vez que, o ensino científico pelo viés da educação e do letramento científico requerem argumentos de qualidade e, neste caso, as pesquisas sobre argumentação também se voltam a analisar a qualidade dos argumentos.

\section{Considerações finais}

O estudo nos revela que, a argumentação no ensino de ciências é uma temática de grande importância para a comunidade científica dado o montante de pesquisa produzidas e pela discussões que os trabalhos/artigos e pesquisas fomentam, uma vez que, as pesquisas não se mostraram rotineiras e de frequência constante, mas sim, há um rol de diversidade de objetivos, ações e resultados obtidos a partir das práticas da argumentação 
científica em sala de aula. Em linhas gerais as pesquisas estão distribuídas também entre as IES, para as disciplinas de foco da ciência da natureza.

É de salutar importância identificarmos nas pesquisas sobre a argumentação científica que para além de promover a construção da argumentação de qualidade, promoverem o desenvolvimento processo de tomada de decisões e no favorecimento do conhecimento científico.

Identificamos também uma produção substancial frente a pesquisas que atuam na construção da argumentação, apesar de que os modelos são tendenciosos o que nos remete a necessidade de pesquisas que possam diversificar este processo.

No que se refere a trabalhos que se pautem no viés das premissas dos elementos de construção da argumentação pautados por Toulmin, identificamos que este continua sendo - Padrão mais efetivo com inserção de outros modelos para a análise da argumentação construída.

\section{Referências}

ALEIXANDRE, María Pilar Jiménez. Diseño curricular: indagación y razonamiento con el lenguaje de las ciencias. Enseñanza de las ciencias: revista de investigación y experiencias didácticas, v. 16, n. 2, p. 203-216, 1998.

ALEIXANDRE, María Pilar Jiménez. Resources for introducing argumentation and the use of evidence in science classrooms. Danú, 2009.

BARDIN, L. Análise de conteúdo. Lisboa: Edições 70, 2006.

BIASOTO, José Eduard; CARVALHO, Anna Maria Pessoa de. Análise de uma atividade experimental que desenvolva a argumentação dos alunos. Fonte: Anais do VI ENPECEncontro Nacional de Pesquisa em Educação em Ciências, 2007.

CIRINO, M. M.; SOUZA, A. R. O discurso de alunos do ensino médio a respeito da camada de ozônio. Ciência \& Educação (Bauru), p. 115-134, 2008.

DA SILVA, Miríades Augusto; DA SILVA, Rejâne Maria Lira. O uso de evidências no desenvolvimento da argumentação de alunos sobre a temática microrganismos, em aulas de ciências naturais. Atas do VIII Encontro Nacional de Pesquisa em Educação em Ciências. Campinas, SP, Brasil

DE MELO, Viviane Florentino; VIEIRA, Rodrigo Drumond; DA ROCHA BERNARDO, José Roberto. A presença de discurso transacional como um indicador de argumentação de qualidade em uma atividade de júri simulado. Anais do X Encontro Nacional de Pesquisa em Educação em Ciências. Águas de Lindóia. Anais, 2015.

DE SOUSA, Polliane Santos; GEHLEN, Simoni Tormöhlen. Argumentação centrada em Questões Sociocientíficas e Educação Problematizadora: algumas relações. Anais do IX Encontro Nacional de Pesquisa em Educação em Ciências. Águas de Lindóia. Anais, 2015. FERREIRA, Jerino Queiroz. Formação inicial de professores de química: explorando possibilidades a partir da promoção de oficinas pedagógicas em argumentação. 2016. Tese de Doutorado. Universidade de São Paulo. 
FERREIRA, N. S. de A. As pesquisas denominadas 'estado da arte'. Educação \& Sociedade, ano 23, p. 257-272, ago. 2002.

FIORENTINI, D. Memória e análise da pesquisa acadêmica em Educação Matemática no Brasil: o banco de teses do CEMPEM/FE-Unicamp. Zetetiké, v 1, n.1, p.55-76, mar. 1993.

FREIRE, Caio Castro; MOTOKANE, Marcelo Tadeu. O uso do raciocínio hipotético dedutivo para promover a argumentação na formação continuada de professores de biologia. Atas do IX Encontro Nacional de Pesquisa em Educação em Ciências. Campinas, SP, Brasil JIMÉNEZ-ALEIXANDRE, M. P. 10 ideas clave: Competencias en argumentación y uso de pruebas. $1^{\text {a }}$. ed. Espanha: Graó, 2010.

LATOUR, B. e WOOLGAR, S. A vida de laboratório: a produção de fatos científicos. Rio de Janeiro: Relume Dumará, 1997

LAWSON, A.E. T. rex, the crater of doom, and the nature of scientific discovery. Science \& Education, v.13, p. 155-177, 2004.

LOCATELLI, R. J. Uma análise do raciocínio utilizado pelos alunos ao resolverem os problemas propostos nas atividades de conhecimento físico. Dissertação de Mestrado. Universidade de São Paulo, São Paulo, 2006.

MENDES, Mírian Rejane Magalhães; SANTOS, WLP. Construção discursiva para a argumentação em discussões sociocientíficas. Atas do IX Encontro Nacional de Pesquisa em Educação em Ciências. Águas de Lindóia-SP, 2013.

MOREIRA, H. R; ROSA, L. M. V; SUART, R. C. Analisando interações argumentativas entre alunos do Ensino Médio e licenciando em química: contribuição para a formação inicial docente. Atas do VIII Encontro Nacional de Pesquisa em Educação em Ciências. Campinas, SP, Brasil. 2011

OSBORNE, J.; ERDURAN, S.; SIMON, S. Enhancing the quality of argumentation in school science. Journal of Research in Science Teaching. v.41, n.10, p.994-1020. 2004

PEREIRA, R. G.; TRIVELATO, S. Estudantes do Ensino Médio utilizam conhecimentos científicos em seus posicionamentos acerca de questões sócio-científicas. Atas do VIII Encontro Nacional de Pesquisa em Educação em Ciências. Campinas-SP, 2011a.

PEREIRA, R. G.; TRIVELATO. Qual o conhecimento é utilizado por estudantes do ensino médio quando discutem sobre temas científicos? Atas do VIII Encontro Nacional de Pesquisa em Educação em Ciências. Campinas-SP, 2011b.

SCARPA, D; TRIVELATO, S. L. F. Características linguísticas e argumentativas de artigos científicos que participaram da construção do paradigma do DNA como portador das informações hereditárias. Atas do VIII Encontro Nacional de Pesquisa em Educação em Ciências. Campinas, SP, Brasil

SILVA, A.H. et al. Análise de conteúdo: fazemos o que dizemos? Um levantamento de estudos que dizem adotar a técnica. Conhecimento Interativo, v. 11, n. 1, p. 168-184, 2017.

SILVA, H. L; JUSTI, R. Analisando o domínio da capacidade de caracterizar evidências e justificativas por parte de professores de Química recentemente formados na Universidade Federal de Minas Gerais. Atas do VIII Encontro Nacional de Pesquisa em Educação em Ciências. Campinas, SP, Brasil 
SIMON, S.; ERDURAN, S.; OSBORNE, J. Learning to teach argumentation: research and development in the science classroom. International Journal of Science Education, v, 28, n. 2-3, 2006. p.235-260.

SOUSA, Taize Borges. O discurso argumentativo em um Curso de Férias: uma análise a partir do Tratado da Argumentação: a nova retórica. Fonte: Anais do XI Encontro Nacional de Pesquisa em Educação em Ciências, 2017

TOULMIN, S. E. Os usos do argumento. 2. ed. São Paulo: Martins Fontes, 2006.

VAN EEMEREN, F. H. et al. Fundamentals of argumentation theory: A handbook of historical backgrounds and contemporary developments. Mahwah, NJ: Lawrence Erlbaum, 1996.

VIEIRA, Rodrigo Drumond; DO NASCIMENTO, Silvania Sousa. Uma proposta de critérios marcadores para identificação de situações argumentativas em salas de aulas de ciências. Caderno Brasileiro de Ensino de Física, v. 26, n. 1, p. 81-102, 2009. 